\title{
Self-efficacy in the Prediction of Academic Performance of Engineering Students
}

\author{
Chun-Ling Huang \\ Mechanical Engineering Department \\ Southern University, Baton Rouge, LA 70813
}

\begin{abstract}
As a result of the eruption of technological advances, careers in the fields of engineering have become areas of high employment opportunities and this trend is expected to remain strong in the future (National Center for Educational Statistics, 1996). Engineering skills are now considered basic tools for acquiring knowledge, managing systems, and solving complex problems in our society. The influence of these two areas is becoming so universal that almost all areas in the work place seem to be affected in some significant way. Moreover, reports from the College Placement Council indicate that the demand for engineers far exceeds the supply. However, in order to take advantage of the numerous career opportunities, students must first complete the educational requirements for engineering and its allied fields (Lent, Brown, \& Larkin, 1986). This paper presents background information relative to the engineering discipline and self-efficacy. Furthermore, the paper will also discuss the results of the study conducted to explore the extent to which variables such as career self-efficacy, math ACT/ SAT score, high school GPA, and vocational interest that could predict the academic performance of engineering students.
\end{abstract}

\section{Introduction}

Engineering disciplines are more and more in demand, however, the supply of academically prepared graduates is inadequate to meet the needs of industry. Many students who enter engineering programs are unable to sustain a satisfactory level of achievement required for program completion [7]. There is need for a counseling tool that will be useful in the selection and preparation of students who enter engineering programs. However, an extensive review of the literature has failed to identify an effective, comprehensive counseling tool that will enable more students to graduate and become productive engineers in industry and business. This framework presented in this paper is designed to extend the findings of Lent et al (1986) and the applicability of Bandura's self-efficacy theory to the process of students' ability to complete the educational requirements of various science and engineering fields.

In particular, results of this framework can be used to provide a useable means for predicting student performance in engineering programs based on measurable parameters. The resulting model, based on the possible importance of career-related self-efficacy beliefs and other career-related variables, is expected to provide an explanation of

Proceedings of the 2003 ASEE Gulf-Southwest Annual Conference

The University of Texas at Arlington

Copyright (C) 2003, American Society for Engineering Education 
academic performance (college GPA) of second-year students enrolled in engineering programs. Furthermore, information gained from this design is expected to allow improvement of advisor effectiveness and career counseling for students.

\section{Main Tenets of Self-Efficacy Theory}

Two decades have passed since Bandura first identified self-efficacy theory as a belief of one's ability to successfully perform a given task. By the end of his first decade of study, Bandura had determined that human functioning might be dependent on cognitive capacities $[2,3]$.

\section{Fundamental Cognitive Capacities}

According to Bandura human cognitive capacities that can predict the individual's performance include the ability to use symbols, learning through observation, planning, self-regulation, and self-reflection [1]. A brief description of each of these human cognitive capacities follows:

Ability to Use Symbols: By the use of symbols, humans transform immediate visual experiences into internal cognitive models that in turn serve as guides for their actions. Through symbolizing, people also ascribe meaning, form and duration to their past experiences.

Learning Through Observations: Learning can also occur indirectly by observing other people's behavior and its outcomes. Individuals' capacity to learn by observation enables them to obtain and accumulate rules for initiating and controlling different behavioral patterns without having to acquire these behaviors by risk trail and error.

Planning: People not only react immediately to their environments through a symbolic process, but also self-regulate their future behaviors by planning. In particular, people plan courses of action for the near future, anticipate the likely consequences of their future actions, and set goals for themselves.

Self-Regulation: Through self-regulatory functions, human behavior is motivated and regulated by internal standards and self-evident reactions. The ability of selfregulation enables people to analyze their experience and to think about their own thought processes [2].

Self-Reflection: The self-reflective capability also called the self-reflective consciousness, enables people to think and analyze their experiences and thought processes. By reflecting on their different personal experiences, individuals can generate a specific knowledge about their environment and about themselves.

\section{Self-efficacy and Learning Outcomes}

Learning outcomes can be broadly labeled into two categories: cognitive and affective. The cognitive outcome is the actual knowledge and skills acquired. The affective outcome is the self-concept changes. The application of self-efficacy beliefs has positive effects on both the outcomes. Bandura suggested that individuals with high self-efficacy exhibit low anxiety, better working styles, and better focus. He also suggested that self- 
efficacy theory combined with behavioral analysis of student performance could improve learning outcomes.

\section{Self-efficacy As A Predictor of Learning Outcomes}

Self-efficacy is an effective predictor of individuals' performance outcomes and has been evidenced in the work of various researchers [6]. Lent, and et al also reported that academic self-efficacy was a good predictor of grade point average. Students who are positive about their academic skills (high self-efficacy) expect high grades on exams and expect the quality of their work to accumulate benefits. The opposite is true for those students who lack such confidence (low self-efficacy). Students who are not sure about their academic abilities envision low grades before they begin an exam [10].

Bandura argued that the outcomes people expect are largely dependent on their judgments of what they can achieve. Students may recognize that strong mathematics skills are important for a good score on the Graduate Record Examination (GRE) and admission to graduate school, which in turn, may guarantee a great career and prosperous lifestyle, but if they have low confidence (low self-efficacy) in their math abilities they may shy away from certain courses and may not bother to take the GRE or apply to graduate school. However, high self-efficacy and negative outcome expectations are likewise possible. For example, a student reasonably confident (high self-efficacy) in her/his physics capabilities may elect not to enroll in a physics course because the professor's grading curve is such as to discourage all but the daring.

Several theorists have acknowledged the importance of self-efficacy theory to the understanding and prediction of career relevant behaviors, such as vocational choices and academic outcomes. Self-efficacy theory has been found to be more vigorous than alternative theoretical systems in explaining and predicting academic performance variables among college students [9].

In contrast, Bandura, has cautioned researchers attempting to predict academic outcomes from students' self-efficacy beliefs that, to increase exactness of prediction, they would be well advised to follow theoretical specifications regarding specificity of self-efficacy assessment and correspondence with criteria tasks. This caution is often neglected in educational research, resulting in self-efficacy assessments that reflect global or generalized self-perceptions of readiness and that bear slight similarity to the criteria tasks with which they are compared. The result is often doubtful relationships and vague findings that confuse the potential contribution of self-efficacy beliefs to the understanding of academic performances [2].

Various researchers have assessed general academic self-perceptions of competence. The basic problem with such assessments is that students must generate these judgments without a clear academic activity or task in mind. Pajares (1996) has suggested that domain-specific assessments, such as asking students to identify their confidence to learn mathematics or writing, are more explanatory and predictive than excluded measures and preferable to general academic judgments. Thus, a growing body of research relating

Proceedings of the 2003 ASEE Gulf-Southwest Annual Conference

The University of Texas at Arlington

Copyright (C) 2003, American Society for Engineering Education 
self-efficacy beliefs to academic outcomes has been generated. The differing role played by beliefs of personal skills versus self-efficacy about likely outcomes continues to be an area of study.

\section{Self-efficacy As A Predictor of Learning Outcomes In Engineering}

Research on career self-efficacy has previously focused on investigations of the relationship of general occupational self-efficacy to students' consideration of a range of career options. However, researchers have since moved toward examining self-efficacy in relation to educational progress and achievement in specific fields.

Lent et al conducted the first studies linking career self-efficacy to academic performance and persistence in engineering fields. Findings of their research are supportive of the utility of the self-efficacy construct. Lent, and et al found that students' beliefs about their ability to complete the educational requirements of various science and engineering fields were predictive of later academic performance. Students declaring relatively strong selfefficacy, generally achieved higher academic grades, and were much more likely persisting in engineering majors than those with low self-efficacy [11].

Following up on their early research with an investigation comparing self-efficacy theory to alternative theoretical paradigms. Lent et al., reported evidence suggesting that selfefficacy is helpful in the prediction of the grades and persistence of engineering majors. Brown, Lent, and Larkin documented the interactions between aptitude and self-efficacy. Brown et al.'s results suggest that strong self-efficacy expectations especially important to the success of moderate ability students as compared to high-ability students, and are also predictive of persistence and grades in engineering fields [5,9].

Hackett et al., conducted a study to examine the relationship of social cognitive variables to academic achievement in engineering programs. A total of 218 students enrolled in the School of Engineering at a midsize West Coast University provided the sample for study. Self-efficacy expectations with regard to engineering were measured in two ways: as overall occupational self-efficacy and as self-efficacy for academic milestones. Hackett et al.'s study suggests that self-efficacy for academic milestones, in combination with other academic and support variables, were found to be the strongest predictor of academic achievement [8].

The aforesaid scholars have used the Science and Engineering Career Questionnaire (SECQ) to measure expectations or self-perceptions of personal efficacy in engineering areas. It was reported that those students who had significantly high scores on the SECQ scale would be more likely to achieve academic progress than those with lower scores.

\section{Self-efficacy and Educational Requirements}

Bandura's self-efficacy theory focused on how beliefs about one's ability to successfully function in a task can increase an individual's confidence. This concept has been applied 
to variety of domains, ranging from the treatment of individuals with phobic problems to areas such as career decision-making academic achievement and persistence.

Lent et al investigated the relationship of self-efficacy beliefs to persistence and success in pursuing science and engineering programs. During a 10-week career-planning course in science and engineering careers, they administered a self-efficacy measure to 28 males and 14 females. Results indicated that those students who reported high self-efficacy expectations in their ability to complete technically related tasks earned higher grades and were able to persist longer in the programs as compared to those students with lower selfefficacy expectations [12].

According to Bandura's social cognitive theory, individuals possess a self-system that enables them to exercise a measure of control over their thoughts, feelings, motivation, and actions. Self-efficacy, a derivative of social cognitive theory, is strongly related to the individual's perceived capabilities to produce results and to attain designated types of performance. In the light of this discussion self-efficacy beliefs can be an excellent predictor of the academic performance of engineering students [2].

\section{Academic Performance Factors}

A study was conducted to extend the findings of Lent et al, and the applicability of Bandura's self-efficacy theory to the process of students' ability to complete the educational requirements of various science and engineering fields. In particular the study identified factors such as: career related self-efficacy beliefs, math SAT scores, high school GPA (HSGPA), and vocational interests (VI) that can predict the academic performance of students enrolled in engineering programs. Multiple linear regression analyses was applied to assess what self-efficacy adds to the prediction of academic performance (college GPA) of students enrolled in engineering courses, above and beyond the measures of math SAT scores, HSGPA, and VI. Specifically, multiple linear regression analysis was used to predict the academic performance (college GPA) of the students in engineering programs at a University in south based on the following variables:

\begin{tabular}{ll} 
Variable & Refers to the \\
\hline y & Academic performance (college GPA) \\
& \\
x1 & Math SAT scores (MAT-SAT) \\
x2 & Vocational Interests (VI) \\
x3 & Academic Milestones-Strength (AM-S) \\
x4 & Educational Requirements-Strength (ER-S) \\
x5 & High School GPA (HSGPA)
\end{tabular}

AM-S (Academic Milestone-Strength) variable is obtained for the strength of selfefficacy. In particular, this variable rates the degree of confidence of the participants in 
their ability to perform specific accomplishments critical to the academic success in engineering majors (e.g., complete the mathematics requirements for most engineering majors).

ER-S (Educational Requirements-Strength) variable is a measure of the strength of selfefficacy and is assessed by having participants rate their degree of confidence in their ability to complete their education requirements.

Parameters estimate for the regression model of male and female students is expressed in Table 1.

Table 1 Parameters estimate for the regression model

\begin{tabular}{|c|c|c|c|c|}
\hline $\begin{array}{c}\text { Independent } \\
\text { Variables }\end{array}$ & $\mathrm{b}$ & $\beta$ & $\mathrm{T}$ & sigT \\
\hline Male & & & & \\
\hline MAT-SAT & .001 & .166 & 1.97 & .051 \\
\hline HSGPA & .107 & .085 & 1.02 & .311 \\
\hline ER-S & .235 & .293 & 2.95 & $.004^{*}$ \\
\hline AM-S & .175 & .210 & 2.27 & $.026^{*}$ \\
\hline VI & .274 & .294 & 2.93 & $.004^{*}$ \\
\hline Female & & & & .778 \\
\hline MAT-SAT & .0002 & .025 & .285 & .577 \\
\hline HSGPA & .058 & .045 & .563 & $.030^{*}$ \\
\hline ER-S & .257 & .360 & 2.26 & $.0003^{*}$ \\
\hline AM-S & .510 & .640 & 5.16 & .475 \\
\hline VI & -.08 & -.093 & -1722 & \\
\hline
\end{tabular}

NOTE: $\left(^{*}\right)$ indicates statistical significance at $\rho<.05$

F statistics is used to determine whether these results, occurred by chance. Table 2 shows statistical significance for both male and female students at .05 alpha level, which suggests that the regression model for both male and female students is useful in predicting academic performance.

Table 2 Analysis of variance for male and female students

\begin{tabular}{|c|c|c|c|c|c|}
\hline $\begin{array}{c}\text { Source of } \\
\text { variation }\end{array}$ & Sum & DF & Mean & F & Sig of F \\
\hline Male & & & & & \\
\hline Regression & 17.88 & 5 & 3.57 & 25.61 & $.000^{*}$ \\
\hline Residual & 11.03 & 79 & .14 & & \\
\hline Total & 26.92 & 84 & & & \\
\hline Female & & & & & $.000^{*}$ \\
\hline Regression & 13.4 & 5 & 2.68 & 34.89 & \\
\hline Residual & 2.61 & 34 & .07 & & \\
\hline Total & 16.014 & 39 & & & \\
\hline
\end{tabular}

NOTE: $\left(^{*}\right)$ indicates statistical significance at $\rho<.05$

Proceedings of the 2003 ASEE Gulf-Southwest Annual Conference

The University of Texas at Arlington

Copyright (C) 2003, American Society for Engineering Education 
The multiple regression equation $\mathrm{y}=\mathrm{m} 1 * \mathrm{x} 1+\mathrm{m} 2 * \mathrm{x} 2+\mathrm{m} 3 * \mathrm{x} 3+\mathrm{m} 4 * \mathrm{x} 4+\mathrm{m} 5 * \mathrm{x} 5+\mathrm{b}$ was used to predict the academic performance of the students in engineering programs. Coefficients $\mathrm{m} 1, \mathrm{~m} 2, \mathrm{~m} 3, \mathrm{~m} 4$, and $\mathrm{m} 5$ were obtained from the SPSS computer program. The F statistic was used to determine whether the results, with high a coefficient of determination, occurred by chance. The t-statistic was used to determine whether each slope coefficient is useful in predicting academic performance. Each independent variable was tested for statistical significance at the 0.05 level. If the observed t- value, is greater than the critical value for all the variables used in the regression equation, then all variables used in the equation will be determined useful in predicting the academic performance of students enrolled in engineering programs.

The following conclusions were deduced based on the findings of research:

1. The mean math SAT score for all the participants was 462 and the variable math SAT was a strong predictor of the academic performance. The results drawn from the statistics showed that the HSGPA represented a minute significance with a beta value of .113 in the prediction of the college GPA. However, the math SAT score significantly contributed in the performance of the students enrolled in engineering programs. The stepwise regression analysis improved the coefficient of the math SAT variable and excluded the HSGPA to provide a better regression equation for predicting the academic performance.

2. The results obtained from the research also indicated that the mean score of selfefficacy was a little higher than the vocational interest mean score. Both self-efficacy and vocational interest were highly correlated with the college GPA, with a value of $(r=.731)$ for self-efficacy and $(r=.681)$ for vocational interest. The beta value $(\beta)$ of almost $50 \%$ indicated the self-efficacy was a strong predictor of the academic performance. However, both the variables, self-efficacy and vocational interest were strong predictors of the academic performance.

3. Finally, results obtained from the research included the variables, math SAT, HSGPA, self-efficacy, vocational interest and academic milestones. The results concluded that the average math SAT scores were almost same for both male $(\mathrm{M}=$ 466) and female $(M=451)$ students.

The results of the regression analysis showed that the HSGPA was not statistically significant in the prediction of the academic performance. For the female students math SAT, HSGPA and vocational interest were not highly correlated to the academic performance.

Self-efficacy $(\beta=.293)$, academic milestones $(\beta=.21)$ and vocational interest $(\beta=.294)$ were strong predictors of the academic performance for the male students.

For the female students academic milestones $(\beta=.64)$ was the highest predictor of the college GPA. However, self-efficacy $(\beta=.36)$ was a significant variable in the predication of the academic performance.

Proceedings of the 2003 ASEE Gulf-Southwest Annual Conference

The University of Texas at Arlington

Copyright (C) 2003, American Society for Engineering Education 


\section{Summary}

This study explored the relation of the self-efficacy beliefs to the academic performance and furthermore assessed the extent to which efficacy beliefs, in concert with other relevant variables such as vocational interest, academic milestones, math SAT scores and high school GPA, predict the academic performance of the students enrolled in engineering programs.

Participants were enrolled in engineering programs at a southern university. Multiple regression analysis indicated that self-efficacy contributed significant unique variance in prediction of the academic performance.

\section{References}

1. Bandura, A., Self-Efficacy: The exercise of control. New York: Freeman, (1997).

2. Bandura, A., Social foundations of thought and action. Englewood Cliffs, NJ: Prentice Hall, (1986).

3. Bandura, A., Self-efficacy: Toward a unifying theory of behavioral change. Psychological Review., 84, 191-214 (1977).

4. Brush, S. G., Women in science and engineering. American Scientist., 79, 404-419 (1991).

5. Brown, S. D., Lent, R. W., and Larkin, K. C. Self-efficacy as a moderator of scholastic aptitude-academic performance relationships. Journal of Vocational Behavior, 35, 64-75 (1989).

6. Bruch, M., Chesser, E. S., and Meyer, V., The role of evaluative self-schemata in cognitive processing and performance: The impact on self-efficacy, self-evaluation and task outcome. Scandinavian Journal of Behavior Therapy, 18, 71-84 (1989).

7. Felder, R. M., Felder, G. N., Mauney, M., Hamrin, C. E., and Dietz, E. J., A longitudinal study of engineering student performance and retention. Journal of Engineering Education., 84, 2, 151-163 (1995).

8. Hackett, G., Betz, N. E., Casas, J. M., and Rocha-Singh., Gender, ethnicity, and social cognitive factors predicting the academic achievement of students in engineering. Journal of Counseling Psychology, 39, 4, 527-538 (1992).

9. Lent, R. W., and Hackett, G., Career self-efficacy: Empirical status and future directions. Journal of Vocational Behavior, 30, 347-382 (1987).

10. Lent, R. W., Brown, S. D., and Larkin, K. C. Self-efficacy in the prediction of academic performance and perceived career options. Journal of Counseling Psychology, 33, 3, 265-269 (1986).

11. Lent, R. W., Brown., S. D., and Larkin, K. C., Relation of self-efficacy expectations to academic achievement and persistence. Journal of Counseling Psychology, 33, 3, 265-269 (1984).

12. National Center for Educational Statistics, 1996. 
CHUN LING HUANG

Chun Ling Huang earned B.S. and M.S. degrees in mechanical engineering from Chung Yuan Christian University (CYCU) in Taiwan, and a Ph.D. degree in mechanical engineering from the University of Alabama (UA) at Tuscaloosa. Currently, he is an associate professor of mechanical engineering in SUBR. He is a member of ASME and ASEE. 